\title{
PERCEPÇÕES DOS ALUNOS SOBRE A AFETIVIDADE NAS AULAS DE INGLÊS DE ENSINO MÉDIO DE UMA ESCOLA TÉCNICA
}

B. A. P. CAVALCANTI
Instituto Federal do Rio Grande do Norte
beatriz.alves@ifrn.edu.br
Artigo submetido em julho/2012 e aceito em setembro/2014
DOI: $10.15628 /$ holos.2014.979

\section{RESUMO}

Este trabalho é resultado de um estudo de caso que procurou investigar como os alunos de uma escola técnica percebiam a afetividade em suas aulas de inglês, por meio da análise de marcas linguísticas que expressavam tais representações, com o auxílio da Linguística Sistêmico Funcional para análise e interpretação dos dados. Utilizamos a metafunção ideacional de Halliday (1994), que observa a escolha dos operadores verbais para idealizar tais representações, realizada pelo sistema de transitividade para ilustrar como as orações são construídas; e a metafunção interpessoal, que trata das relações entre professor e aluno. O Sistema de Avaliatividade (MARTIN; WHITE, 2005) foi utilizado para analisar as escolhas relacionadas às atitudes de julgamento e afeto feitas pelos alunos. As escolhas lexicais nas narrativas dos alunos sugerem que a afetividade é percebida como elemento integrante das aulas de inglês dessa escola, observada na disponibilidade do professor em ajudar os alunos, na interação entre eles, mas ainda há posturas autoritárias do professor na sala de aula.

PALAVRAS-CHAVE: Afetividade; Linguística Sistêmico Funcional; Representações.

\section{STUDENTS' PERCEPTIONS OF AFFECTIVENESS IN THE ENGLISH CLASSES OF A TECHNICAL SCHOOL}

\begin{abstract}
This paper is the result of a research which tried to investigate how the students of a technical school notice affectiveness in their English classes, observing the linguistic signs that expressed such representations, with the support of the Systemic Functional Linguistics to analyse and interpret the data. We used the Ideational metafunction of Halliday (1994), by means of the Transitivity System to show how the clauses illustrate these representations, and the Interpersonal
\end{abstract}

Metafunction to show the relationship between the teacher and the students. The Appraisal System (MARTIN; WHITE, 2005) was used to analyze the choices related to judgement and attitudes of the students. The lexical choices seem to indicate that affectiveness is noticed as a composing element of the English classes in that school, and it is observed in the teacher's disposition to help the students, in their interaction, but there is still authoritative behavior from the teacher in some classes.

KEYWORDS: Affectiveness; Systemic Functional Linguistics; Representations. 


\section{INTRODUÇÃO}

Este trabalho é resultado de uma investigação sobre como a afetividade é percebida nas aulas de inglês de uma escola técnica. As narrativas de aprendizagem dos alunos (BARCELLOS, 2009) foram submetidas ao programa computacional Wordsmith Tools (SCOTT, 2009), e o mesmo indicou os vocábulos mais utilizados pelos alunos para se referirem ao professor e às aulas de inglês, e assim identificamos as marcas linguísticas que expressam as representações construídas pelos alunos sobre afetividade nessas aulas.

Utilizamos a Metafunção Ideacional de Halliday (1994), realizada pelo Sistema de Transitividade, para ilustrar como as orações são utilizadas para realizar tais representações; a Metafunção Interpessoal, para expressar as relações entre os participantes da pesquisa, bem como a avaliação do escritor sobre a verdade de sua mensagem e sua responsabilidade sobre ela. Os mecanismos linguísticos avaliativos presentes nas narrativas foram analisados pelo Sistema de Avaliatividade, que permite observar atitudes de afeto, julgamento, apreciação de algo, e indicou posturas de julgamento e de afeto em relação aos professores e às aulas.

As escolhas lexicais sugerem que a afetividade é percebida como elemento integrante das aulas de inglês dessa escola, além de ser considerada como um elemento de articulação de primeira ordem nas representações dos alunos, bem como a disponibilidade em ajudar, mas ao mesmo tempo revela que ainda se encontram comportamentos autoritários de professores em algumas aulas.

O resultado da pesquisa pode ajudar o professor de língua inglesa a fazer uma reflexão crítica de sua conduta e das estratégias utilizadas na sala de aula por meio da observação das representações construídas pelos alunos e apresentadas em suas narrativas.

A finalidade da educação é o desenvolvimento holístico da personalidade humana, incluindo aspectos cognitivos e emocional-afetivos. O papel do docente no século XXI é o de um educador que conheça e oriente a aprendizagem discente por meio do apoio emocional e afetivo. Concentrar-se apenas em avaliar as capacidades linguísticas e lógicas durante a escolaridade formal pode levar a um fracasso do sistema educativo; por isso, desenvolver competências afetivas pode ser mais necessário do que experimentar somente desenvolvimento cognitivo (CUBERO, apud. MOSQUERA et al., 2009).

\section{A AFETIVIDADE NO ENSINO DE INGLÊS}

O filósofo grego Zenão de Cítio (que viveu entre os séculos III e II a. C.), fundador do estoicismo, preconizava que a virtude, a sabedoria e o caráter íntegro dominavam as emoções. Cícero partilhando das mesmas ideias, culpava as paixões pelo distanciamento da razão, e as emoções eram consideradas o veneno da alma. O filósofo Aristóteles (que viveu no século III a.C.), no entanto, acreditava que o corpo e a mente se integravam e eram componentes de uma mesma unidade (ROMERO, 2007).

Descartes, filósofo francês conhecido pela célebre afirmação "Penso, logo existo", mote fundador do racionalismo, demonstrava muito bem a concepção de uma mente racional, desconsiderando o lado emocional. No final do séc XVII, o filósofo holandês Spinoza propôs a ideia 
de corpo e alma como complementares em sua obra "Ética". Esses posicionamentos divergentes ainda se refletem nas teorias mais atuais que abordam a construção do conhecimento.

Segundo Castro (2007), na área do ensino de inglês, o tema da afetividade começou a ser discutido no final dos anos 1960, como uma resposta aos "drills" ${ }^{1}$ utilizados no ensino de inglês da época. Entre os anos 1960 e 1980, a afetividade no ensino de uma forma geral prioriza o aprendiz, reconhecendo-o como um dos elementos fundamentais integrantes no processo de ensinoaprendizagem e estabelece que as características individuais do aluno podem interferir e contribuir nesse processo e, por isso, os professores são sensibilizados para os valores e relações humanas que ocorrem na aula de inglês. Ademais, atribui-se muita importância à qualidade de interação na sala de aula, elevando assim o papel da afetividade no ensino de inglês.

Arnold (1999), ao situar a afetividade no contexto do ensino de uma forma geral, pontua que o lado afetivo da aprendizagem não está em oposição ao lado cognitivo, e que quando ambos são usados juntos, o processo cognitivo pode ser construído sob uma formação sólida. Nenhum dos dois aspectos tem a última palavra, e na realidade são indissociáveis. No séc. XXI, percebemos uma tentativa do homem de conceber a razão e a construção do pensamento e do conhecimento, e isso ocasiona mudanças na educação, principalmente na postura do ensino tradicional em que a emoção, obedecendo ao direcionamento vigente, não era considerada no momento de planejar a aula. As aulas de inglês são mais centradas nos alunos, e procuramos observar as necessidades desses alunos, para obtermos uma maior participação nas aulas e, consequentemente, um melhor resultado no processo de aprendizagem da língua.

Krashen (1987) relata que os professores precisam trabalhar na motivação, nos níveis de ansiedade e estimular a autoconfiança do alunos através de um ensino afetivo. Aprendizes motivados, confiantes e com baixa ansiedade apresentam melhores resultados no processo de aquisição de uma segunda língua. O autor sugere a existência de um filtro afetivo constituído pelas emoções dos aprendizes, como motivação, ansiedade e autoconfiança. O filtro afetivo alto se caracteriza pela alta ansiedade, falta de motivação e de autoconfiança, por isso o professor precisa trabalhar com filtro afetivo baixo, estimulando atitudes positivas e a autoconfiança dos alunos na aquisição de uma segunda língua.

\section{A LINGUÍSTICA SISTÊMICO FUNCIONAL E A AFETIVIDADE}

A Linguística Sistêmico Funcional (LSF) surgiu a partir da década de 1960 e foi desenvolvida por Michael Halliday. A LSF concebe a língua como um sistema social organizado que procura dar significado à experiência humana.

Expressamos afeto por meio de sentimentos ou indicando o estado emocional: como o falante/escritor se sente em relação aquele acontecimento? Pode ocorrer gramaticalmente com operadores verbais de processos mentais, como gostar, temer, apreciar, ou por avaliações de atitudes com o operador verbal ser associado a adjetivos, além de advérbios. A LSF observa essas escolha lexicais para interpretar os acontecimentos, apontando que a opção por um vocábulo, ou um determinado operador verbal tem uma intenção específica de representação.

\footnotetext{
${ }^{1}$ Drills são exercícios de repetição de palavras ou estruturas, baseado no estruturalismo americano e na psicologia berhaviorista dos anos 50-60 (HUBBARD, 1993).
} 
Halliday (1994) elaborou uma teoria da língua como escolha. Afirma que a língua é sistêmica e funcional, pois todo texto se desenrola no contexto de uso com uma função. Em cada interação ou produção textual são três tipos de significados que são trocados simultaneamente: significados ideacionais para expressar os acontecimentos; significados interpessoais que expressam as interações, as relações de hierarquia e afetividade; e significados textuais, relacionados à forma da organização e do conteúdo da mensagem. Para Halliday, uma análise de discurso precisa valer-se de aspectos gramaticais; caso contrário, não passará de comentários aleatórios de um texto. Por isso, nos apoiamos em sua teoria para observar os itens lexicais mais frequentes nas narrativas de aprendizagens dos alunos, e a partir desses elementos contextualizados, poderemos interpretar o que ocorre nas aulas de inglês dessa escola técnica.

\section{A PESQUISA}

Esta pesquisa surgiu da prática da pesquisadora em uma escola técnica na cidade de Natal, e do desejo de verificar como a afetividade é percebida pelos alunos nas aulas de ingês, pois , a princípio, pode-se ter a ideia de um ensino tecnicista, cujo foco é o processo de aquisição de habilidades no curso técnico.

Participaram 68 alunos, sendo 21 da turma de Geologia (Geo M), 22 da turma de Controle Ambiental (ConAmb M), e 25 de Turismo (Tur V). A escolha dos cursos foi aleatória. Solicitamos que os alunos narrassem uma aula de inglês que eles já tivessem participado, que eles considerassem boa e outra ruim, mencionando disposição da sala, interação, reação de todos, entre outras informações.

Utilizamos narrativas de aprendizagem como instrumento de pesquisa, já que são muito utilizadas para estudar as crenças e representações dos alunos e professores, pois capturam a essência e experiência humana e consequentemente da aprendizagem (BARCELLOS, 2006). Após o recolhimento das narrativas escritas, processamos os dados, submetendo-os ao programa computacional WordsmithTools (SCOTT, 2009) que indica a frequência dos itens lexicais mais utilizados nos textos. Obtivemos assim, os seguintes dados (Tabela 1):

Tabela 1: Ocorrências analisadas nas três turmas

\begin{tabular}{|l|c|c|c|c|}
\hline Item analisado & Turismo & Geologia & Controle & $\begin{array}{c}\text { Total das } \\
\text { ocorrências }\end{array}$ \\
\hline Polaridade negativa: "não" & 51 & 49 & 74 & 174 \\
\hline Grupo nominal“o/a professor/a/” & 50 & 40 & 50 & 140 \\
\hline Adjunto de intensidade: “muito" & 22 & 26 & 27 & 75 \\
\hline Processo mental: "gostar" & 40 & 17 & 23 & 80 \\
\hline Processo relacional: "ser" & 72 & 87 & 85 & 244 \\
\hline Processo relacional “estar” & 9 & 12 & 12 & 33 \\
\hline
\end{tabular}

O elemento lexical mais utilizado pelos alunos foi o índice de polaridade negativa "não", que afirma que algo não é de determinada forma. A LSF denomina este item como índice de polaridade negativa, analisado pela metafunção interpessoal. A polaridade é a escolha entre o sim e não, por isto pode ser positiva ou negativa, mas nem sempre a polaridade negativa tem uma 
denotação negativa. O que determina é o contexto. Nas narrativas dos alunos este item lexical obteve $61,5 \%$ de representações positivas.

Ex 1: A professora interagiu, dizendo as palavras que não conhecíamos. (A15 ConAmb M)².

A polaridade negativa foi utilizada para se referirem ao comportamento ou reação dos alunos durante as aulas, ou a procedimentos utilizados pelo professor que não os deixavam com medo de falar, e também para mencionar que tipo de aulas não apreciavam ou atitudes do professor que desaprovavam.

Ex.2 Uma aula que não gostei, foi quando o professor pediu para a turma ficar traduzindo uns textos, porque assim não praticamos tanto o inglês (A 23 Tur V)

Ex.3: E com a ajuda da professora, quando não se entendia a pronúncia da gravação, facilitou o aprendizado (A 4 Geo M).

Ex.4: Uma brincadeira, etc., não deixa a aula com "cara" de aula mesmo, e deixa o aluno mais à vontade (A 11 Geo $M$ ).

Ex.5: O professor não passava filmes de graça, ele cobrava análises do filme, através de resumos ( $\mathrm{A} 3 \mathrm{Geo} M)$.

O grupo nominal o(a) professor(a), associado a processos materiais que, por sua vez, expressam os acontecimentos, foi utilizado em $64,3 \%$ das ocorrências para demonstrar a aprovação na forma como conduzia as aulas ou se relacionava com os alunos, a utilização de diversos recursos e estratégias que estimulavam diversos estilos de aprendizagem (RICHARDS, 2005).

Ex. 6: O professor fez com que todos falássemos a vontade, mesmo com erros. (A 25 Tur V). TurV).

Ex. 7: O professor nos recebeu de uma forma agradável onde não tememos falar (A 17

Ex. 8: Meu professor realizou uma aula tão divertida, que tentei me familiarizar com esta matéria (A 7 Geo M).

Ex. 9: O nosso professor exibia filmes bem legais (A 5 Geo M).

Os alunos também mencionaram comportamentos e procedimentos que podem tornar a aula mecânica e sem estímulos:

\footnotetext{
${ }^{2}$ Leia-se: "A" - Aluno; “Geo" - Geologia; “ConAmb” - Controle Ambiental; “Tur" - Turismo; “M” - Matutino; “V” Vespertino.
} 
Ex. 10: Foi um dia da prova oral, quando o professor chegou atrasado, e ao fazermos uma pergunta a ele, ele nos respondeu mal (A 19 Tur V).

Ex: 11: Aula ruim é aquela em que o professor simplesmente passa o conteúdo, como se o aluno fosse um gravador (A 1 Tur $V$ ).

Ex. 12: Tudo parecia muito mecânico, e preso ao livro didático, e o professor se punha a falar português (A 20 Tur V).

Ex.13: As piores aulas são aquelas em que o professor apenas lê o conteúdo e responde as atividades sem nenhuma participação (A 21 Geo M).

Utilizaram o adjunto de intensidade muito como intensificador de um operador verbal:

Ex.14: Acho que todos se divertiram muito, pois todos sairam felizes da aula (A 21 Tur V).

Ex.15: Nós gostamos muito da aula em que a professora passou os episódios da série Friends (A 8 ConAmb M).

O uso do adjunto de intensidade sugere a valorização das aulas dinâmicas e significativas para eles, como visitas ao shopping, onde aprendem a utilização do idioma numa situação de compras, ou no supermercado, lanchonetes, e outros lugares. Apesar de não serem situações reais, por não estarmos em um país onde a língua inglesa é falada oficialmente, há um estímulo para praticar a oralidade numa situação fictícia, pois a língua inglesa não é trabalhada oralmente todos os dias na sala de aula. Aulas com músicas, em que todos cantam e interagem, e outros tipos de aulas em que os alunos são estimulados a participar e interagir reforçam as ideias de Vygotsky (1991), quando afirma que a aprendizagem se dá na interação com o outro.

Os alunos também utilizaram o adjunto de intensidade junto a um predicativo para expressar, com ênfase, as aulas que apreciam ou não. Analisando os contextos em que encontramos este item lexical, percebemos críticas à educação bancária, mencionada por Paulo Freire (1987), em que os saberes dos alunos não são considerados. Não há interação, somente transmissão de informação. A conduta de um professor que teve uma postura agressiva em uma determinada aula foi muito criticada pelos alunos na turma de Turismo:

Ex: 16: Uma aula que não gostei foi quando o professor chegou estressado porque perdeu um cd e acabou sendo muito grosseiro (A 11 Tur V).

Ex.17: Isto foi muito ruim porque ele era considerado um bom professor, até o momento (A 5 Tur V).

Ex.18: As aulas que menos gosto são as menos dinâmicas, as expositivas, muito sérias. $\mathrm{Na}$ minha opinião, o inglês é uma língua, que dá para aprender brincando (A 8 Geo M).

Ex.19: O professor só falou do assunto, não foi uma aula muito interessante, porque foi muito parada, e ninguém prestou muita atenção ( 9 Geo M).

Ex.20: As aulas muito presas ao livro, deixando a aula não muito interessante (A 2 ConAmb M). 
Em relação aos operadores verbais, os mais utilizados foram ser e estar, que expressam o processo relacional para estabelecer uma relação entre entidades, para classificá-las, identificá-las ou defini-las. Os alunos elogiaram aulas interativas, que não se destinam apenas ao ensino da gramática, apreciam aulas que acontecem em outros ambientes que não sejam apenas a sala de aula:

Ex.21: A aula foi ótima, pois fez a sala interagir com o professor e todos os alunos entre si (A 16 Geo M).

Ex.22: Esta aula foi interessante porque além do filme ser bom ele contribuiu para o meu aprendizado em Inglês (A 15 ConAmb M).

Ex.23: Também é interessante atividades como filmes, aulas fora da sala e etc. (A11 Geo M).

Todos esses elementos são características de um ensino humanístico, como propõe Moscowitz (1978), no qual se busca humanizar o ensino, sem considerar apenas o lado cognitivo, preocupando-se com o desenvolvimento integral do aluno, ou seja, tanto o lado racional quanto o emocional devem estar presentes na aula.

O operador verbal gostar, que indica um processo mental que expressa afeição, foi escolhido pelos alunos para representar seus gostos, sentimentos e suas experiências nas aulas de inglês. Eles não apreciam aulas em que haja apenas transmissão de conteúdos sem interação, e demonstram desconforto nas aulas que seguem a educação bancária, como as que mostramos a seguir:

Ex. 24: As aulas que mais gostei foram aulas nas quais, nós alunos interagíamos além da leitura e escrita (A 17 Geo M).

Ex.25: Gostei de uma aula interativa com um filme (A 10 Geo M).

Ex. 26: Não gosto de aulas onde não é admitido nenhuma atividade extra, e também só é ministrado o conteúdo (A 11 Geo M).

Ex.27: Não gostei: as aulas teóricas em geral, pois são monótonas, os alunos não se concentram e acaba por perder o interesse (A 13 ComAmb M).

O Sistema de Avaliatividade (MARTIN; WHITE, 2005) expressa a atitude do escritor/falante em relação ao que se diz nos textos, mostra as avaliações que os alunos fazem de seus professores e das aulas, como podemos ver no quadro a seguir (Tabela 2): 
Tabela 2: Avaliação dos alunos da turma de Controle Ambiental (adaptação de DROGA; HUMPFREY, 2005).

\begin{tabular}{|c|c|c|c|c|}
\hline Gradação & Item lexical & Item avaliado & Categoria & Valor \\
\hline Muito & gostamos & Aula & Afeto & Positivo \\
\hline & gostei & Aula & Afeto & Positivo \\
\hline & gostei & Aula & Afeto & Positivo \\
\hline & gostei & Aula & Afeto & Positivo \\
\hline & gostei & Aula & Afeto & Positivo \\
\hline & não gostei & Aula & Afeto & Negativo \\
\hline & não gostei & Aula & Afeto & Negativo \\
\hline & interessante & Aula & julgamento & Positivo \\
\hline & divertida & Aula & julgamento & Positivo \\
\hline & dinâmica & Aula & julgamento & Positivo \\
\hline
\end{tabular}

Estes alunos relatam fatos sobre o comportamento dos professores e deles mesmos nas aulas de inglês, ou seja, sempre mencionam de alguma forma a afetividade, seja na forma como o professor se relaciona com os eles, ou na disponibilidade em ajudá-los, ou na interação que ocorre nas aulas. Utilizam, como recursos linguísticos, grupos nominais, operadores verbais, adjetivos e advérbios para a concretização desse Sistema, de forma contextualizada em suas narrativas para expressarem a representação que possuem das aulas de inglês e do relacionamento com os professores.

\section{CONSIDERAÇÕES FINAIS}

Os resultados da pesquisa sugerem que, apesar de algumas posturas típicas da educação cartesiana e tradicional, há a predominância da concepção humanística, oposta à abordagem tecnicista; e a afetividade é considerada como elemento integrante na construção do conhecimento, sendo percebida pelos alunos nas aulas interativas, na utilização de diversos recursos para contemplar diferentes estilos de aprendizagem, nas músicas, filmes e jogos que tornam as aulas mais interessantes e divertidas. O professor trabalha na motivação desses alunos, permitindo que participem de decisões, considerando as suas necessidades e tratando-os como parceiros no processo de aprendizagem, e não somente como receptores de conteúdo.

A metafunção ideacional, utilizada para analisar os processos mentais e relacionais, parece sugerir que os alunos gostam das aulas dinâmicas, que promovam interação e participação dos alunos, e são incentivados pelos professores de inglês, confirmando, mais uma vez, a representação positiva em relação à afetividade. Isso foi observado pela utilização do operador verbal gostar, que exprime um processo mental que retrata a afetividade, e do verbo ser, que é utilizado para identificar ou atribuir qualidades ou julgamentos ao tema em questão.

Concluímos que o ideal é a mistura da razão com a emoção, pois em um ensino tradicional, que se utilizava mais da razão,também foi muito útil para muito de nós aprendermos. Ele funcionou, e por isso, não podemos desmerecê-lo. Sempre haverá momentos em que ensinaremos algo que os alunos podem não apreciar, mas que é indispensável ao aprendizado da língua. Podemos e devemos adicionar elementos que possam contribuir para facilitar o processo de ensino/aprendizagem, e a consideração dos aspectos afetivos no aprendizado da língua inglesa é um grande aliado do professor no processo de aprendizagem. 
Essa pesquisa se baseou nas narrativas de alguns alunos de três turmas distintas de Ensino Médio. Por isso, não pode representar o que acontece no universo de todas as turmas dessa escola; mas, apesar de suas limitações, como a própria subjetividade do tema, esse estudo de caso parece indicar uma postura humanista ou afetiva por parte dos professores de inglês das turmas pesquisadas, pois as aulas são interativas e há uma preocupação com anseios e necessidades dos alunos, e pode ser uma referência para outros estudos futuros que venham discutir a temática da afetividade no ensino de línguas, de representações na área de educação, e da utilização da LSF para análise de textos, partindo das escolhas léxico-gramaticais para a interpretação do contexto em que a pesquisa está inserida.

\section{REFERÊNCIAS}

1. ARNOLD, J. Affect in language learning. Cambridge: Cambridge University Press, 1999.

2. BARCELOS, A. Narrativas, crenças e experiências de aprender inglês. Viçosa: Editora da UFV, 2006.

3. CASTRO, S. O desenvolvimento do componente afetivo da aprendizagem de língua estrangeira em curso de letras: fator crucial para a formação do futuro professor. In: . Cognição, afetividade e linguagem. Taubaté: Cabral Editora universitária, 2007.

4. DROGA, L; HUMPFREY, S. Grammar and meaning: an introduction for primary teachers. Berry: Target Texts, 2005.

5. FREIRE, P. Pedagogia do oprimido. Rio de Janeiro: Paz e Terra, 1987.

6. HALLIDAY, M. A. K. Introduction to functional grammar. London: Edward Arnold: 1994.

7. KRASHEN, S. Principles and Practice in Second Language Acquisition. Prentice-Hall International, 1987.

8. MARTIN, J. R; WHITE, P. The language of evaluation: appraisal in English. London: Palgrave Macmillan, 2005.

9. MOSQUERA, J; STÖBAUS, C. Educação pela afetividade: considerações para futuros educadores. In: ERINCONE, Délia. Professor como aprendiz: saberes docentes. Porto Alegre: EDIPUCRS, 2009.

10. ROMERO, T.R. A dimensão afetiva no processo de reflexão crítica. In: Cognição, e linguagem. Tania Romero. Taubaté: Cabral Editora Universitária,2007.

11. VYGOTSKY, L. S. A formação social da mente. São Paulo: Martins Fontes, 1991. 